\title{
Friction Coefficient and Compression Behavior of Particle Reinforced Aluminium Matrix Composites
}

\author{
A. Ugur \\ Mechanical Engineering Department \\ Engineering Faculty \\ Karabuk University, Karabuk, Turkey \\ augur@karabuk.edu.tr \\ G. Sur \\ Mechanical Engineering Department \\ Engineering Faculty \\ Karabuk University, Karabuk, Turkey \\ gokhansur@karabuk.edu.tr
}

\author{
H. Gokkaya \\ Mechanical Engineering Department \\ Engineering Faculty \\ Karabuk University, Karabuk, Turkey \\ hgokkaya@karabuk.edu.tr \\ N. Eltugral \\ Metallurgical and Materials Engineering Department \\ Engineering Faculty \\ Karabuk University, Karabuk, Turkey \\ nurettineltugral@karabuk.edu.tr
}

\begin{abstract}
Metal matrix composites (MMCs) are materials used in a large range of engineering applications. In this paper, the relatively low-cost stir casting is evaluated with the use for Silisyum Carbite (SiC) as reinforcement and Al7075 alloy as matrix to produce MMCs with varied reinforcement from $10 \%$ to $18 \%$. The produced composites were examined, and their wear behavior was investigated. The results showed that the mechanical properties of the MMCs decrease with the increase of the mass percentage of reinforcement and compression.
\end{abstract}

Keywords-metal matrix composites; stir casting; SiC; friction coefficient

\section{INTRODUCTION}

Aluminum and its alloys play an important role in the production of MMCs. These materials began to be used towards the end of the 20th century, especially in the automotive space and aviation industry. They attract attention due to their specific strength, light weight, heat insulation and high abrasion resistance. Composite material production and material properties can be improved by changing the types and amounts of matrix and reinforcement elements [1-3]. Today, methods such as infiltration, powder metallurgy, rapid solidification, plasma spray hot stamping $[4,5]$ and stir casting [6-8] are used on MMC material production. Stir method is the most economical and with higher product capacity process for production of MMCs. But, stir casting technique, is difficult to produce a homogenous and stable material due to inherent stir casting problems such as poor wetting, clustering and prosite [9-11]. The mechanical properties of MMCs are affected by the interface bond between the matrix and the reinforcing materials and the load transfer is decreased.

Authors in [12] studied aluminum alloy 6061 reinforced with $\mathrm{Al}_{2} \mathrm{O}_{3}$ particles with different mass ratio for the fabrication and characterization of AA $6061 / \mathrm{Al}_{2} \mathrm{O}_{3}$ AMMC by stir casting process. They found some improvement about micro hardness and ultimate tensile strength in produced samples. A17075 material was used as matrix due to its lightness and relatively high strength. Authors in [13] studied 7075 alloy as a matrix with whisker reinforced composites with squeeze casting method for manufacturing superplastic material and succeeded $260 \%$ total elongation. Authors in [14] used 7075 alloy as a matrix to produce $(\mathrm{SiC}+\mathrm{Ti})$ hybrid composites using squeeze casting method. They successfully produced hybrid composite material with increasing strength due to decreasing ductility. Authors in [15] studied 7075 alloy as matrix to produce nano hybrid composites using stir casting and squeeze casting improving the hardness of composites [15].

There are three types of composite reinforcements, long or fibers, finite length fibers and particulates. In our study $\mathrm{SiC}$ particles are selected as a reinforcement material. Authors in [16] used $\mathrm{SiC}$ particles as reinforcement. As a result the material strength increased along with a loose on ductility. Authors in [17] used SiC particles as a reinforcement with Al6061 matrix composites while investigating wear behavior and sliding speed in different $\mathrm{SiC}$ ratios. As a result, in increasing $\mathrm{SiC}$ ratio the wear decreases and friction coefficient increases. Authors in [18] used $\mathrm{SiC}$ as reinforcement with Al6063 matrix to produce composites with vacuum molding assisting stir casting method and to investigate the effect of reinforcement ratio and particle size on dry sliding wear. As a result they found optimum tribological behavior on $7.5 \%$ reinforcement ratio and 70AFS particle size. Authors in [19] used $\mathrm{SiC}$ particles with two different matrix alloys (A536, 6061) and studied reinforcement distribution and wettability improving the wettability of SiC. Authors in [20] used SiC and $\mathrm{C}$ nano tubes as reinforcements to the cooper matrix to produce hybrid self-lubricating composites, and investigated their wear and friction behavior. The resulted hybrid composites showed higher tribological behavior than monolithic copper [20]. Authors in [21] studied magnesium matrix composites 
reinforced with $\mathrm{SiC}$ particles using semisolid stirring assisted ultrasonic vibration method. They found that the composite mechanical properties mostly depend on grain refinement and particle distribution. Authors in [22] produced aluminum matrix composites with $\mathrm{Al}_{2} \mathrm{O}_{3}$ particles. The product microstructure and its mechanical properties were investigated via extrusion processes. They found that porosity increased by increasing reinforcement ratio and stirring speed and decreased by extrusion process. The samples' mechanical properties were usually increased.

A limited number of studies is available on the development of AL7075 aluminum alloy based MMCs by a combination of stir casting method. In this work, different weight percentage of $\mathrm{SiC}$ particle reinforced AL7075 aluminum alloy matrix composites were produced by stir casting. Mechanical and microstructural observations between the aluminum alloy and $\mathrm{SiC}$ were described.

\section{EXPERIMENTAL PROCEDURE}

A17075/10wt SiC, A17075/14wt SiC, A17075/18wt SiC, composite materials were produced. Al7075 was selected as matrix material. The chemical constituents of the material are listed in Table I. This alloy contains $2.7 \% \mathrm{Mg}$ which increases wettability. SiC particles of $50-100 \mu \mathrm{m}$ in size were used as reinforcement elements. The production work was carried out in a specially prepared stir casting machine (Figure 1).

TABLE I. CHEMICAL COMPOSITION OF AL7075

\begin{tabular}{|c|c|c|c|c|c|c|c|c|c|}
\hline $\mathbf{F e}$ & $\mathbf{S i}$ & $\mathbf{C u}$ & $\mathbf{M n}$ & $\mathbf{M g}$ & $\mathbf{Z n}$ & $\mathbf{C r}$ & $\mathbf{Z i}$ & $\mathbf{T i}$ & Rest \\
\hline 0.5 & 0.5 & 1.5 & 0.3 & 2.7 & 5.6 & 0.23 & 0.25 & 0.15 & $\mathrm{Al}$ \\
\hline
\end{tabular}

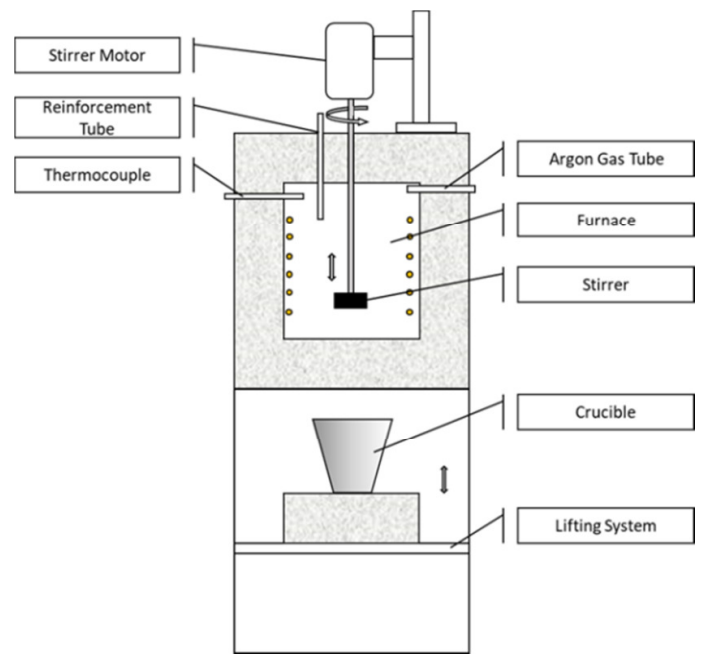

Fig. 1 Mixing casting machine

$\mathrm{A} 17075$ was selected as the matrix material, and was heated to $690^{\circ} \mathrm{C}$ under argon gas, and then the $\mathrm{SiC}$ reinforcing particles, heated at the same temperature were added in packs. The addition continued for 10 minutes at a rate of $200 \mathrm{rpm}$. During this mixing process the temperature dropped to around $590^{\circ} \mathrm{C}$. We may say the study occurred in semi solid state rather than liquid state. After the mixing process, the temperature increased to $720^{\circ} \mathrm{C}$ to increase the fluidity of the composite material, and then it was poured into a pre heated at $350^{\circ} \mathrm{C}$ mold. When it was cooled to room temperature, $500 \mathrm{~g}$ of composite material were produced. A produced test sample is shown in Figure 2. Samples were cut with a finger milling machine and a precision saw was used to give the same shape. For metallographic observation, they were prepared by grinding through 1000 grit papers followed by polishing with diamond paste. The samples were examined with SEM devices. The same samples were prepared as per ASTM E9 standard for compression testing at room temperature, with $20 \mathrm{~m} / \mathrm{s}$ velocity. To obtain friction coefficient a UTS TRIBOMETER T10/20 was used. Samples were prepared on ASTM G-33 standard. $20 \mathrm{~N}, 30 \mathrm{~N}, 40 \mathrm{~N}$ forces were applied on the samples in $200 \mathrm{~m}$ distance for wear test.

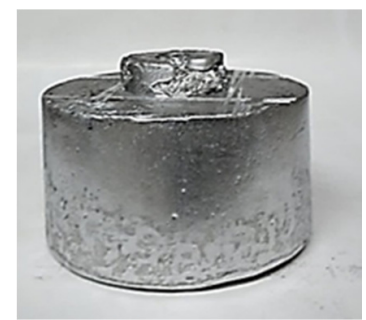

Fig. 2 Sample obtained after casting

\section{RESULTS AND DISCUSSION}

\section{A. Friction Coefficient}

The friction coefficients for different test loads and samples are listed in Table II and their graph is shown in Figure 3. Normally friction coefficient of aluminum - steel couples is 0.5-0.6 and increases with the test distance [23]. The result shown in Figure 4 is analogous to that. Also, an increase in load increases friction coefficient. Generally, in low loads composites shown good tribological characteristic [24]. The values obtained from the test were adjusted to a 6th degree curve to reduce noise. The increase in the ratio of the reinforcement element at a load of $40 \mathrm{~N}$ obtained a lower drag coefficient. Friction coefficients increased due to the increase in distance and wear of the contact surface in the material.

\section{B. Compressive Stres}

Composite materials had different mechanical properties according to particle size and matrix alloy. The results of the test are given in Figure 4. When the $\mathrm{SiC}$ reinforcements increasedat room temperature, the strength of the composite material decreases $[25,26]$. The $10 \%$ SiC-containing sample showed a sudden strain drop due to the progression of capillary cracks. It was observed that the increase in the $\mathrm{SiC}$ ratio caused a decrease in compressive strength due to the fact that the grain size is above 50 microns and porosity occurred in the microstructure during production.

TABLE II. DIFFERENT STATES FOR THE SAMPLES.

\begin{tabular}{|c|c|c|}
\hline Sample & Mass\% SiC & Method \\
\hline $\mathrm{A} 17075-\mathrm{SiC}$ & 10 & Free Casting \\
\hline $\mathrm{A} 17075-\mathrm{SiC}$ & 14 & Free Casting \\
\hline $\mathrm{A} 17075-\mathrm{SiC}$ & 18 & Free Casting \\
\hline
\end{tabular}




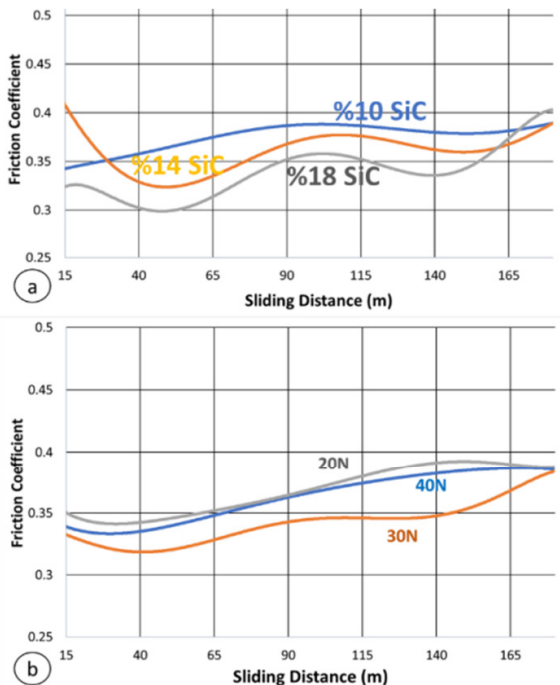

Fig. 3 Friction Coefficient: (a) on $40 \mathrm{~N}$ load for samples 1-3, (b) on $20 \mathrm{~N}$, $30 \mathrm{~N}, 40 \mathrm{~N}$ laod for $10 \% \mathrm{SiC}$ content composites.

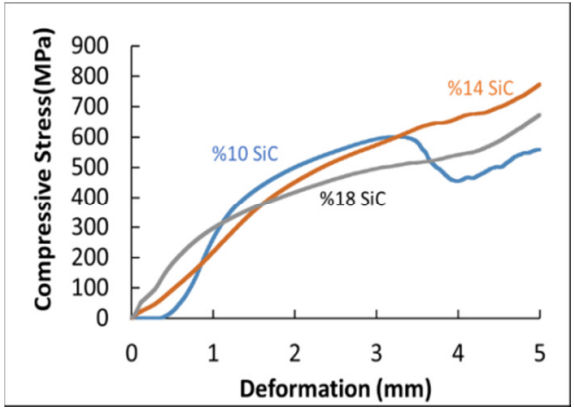

Fig. 4 Compressive stress
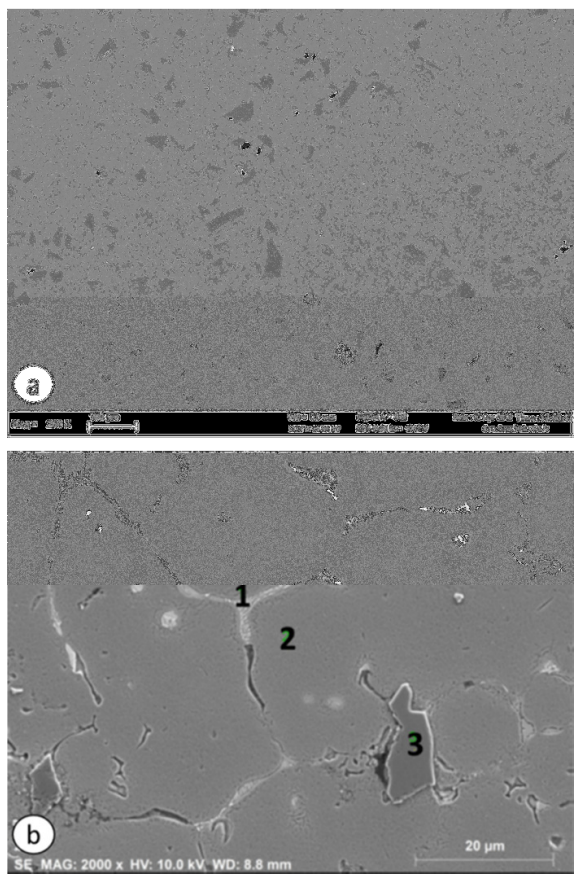

Fig. 5 (a) SEM 1-3, (b) XRD samples

\section{Microstractural Characterization}

The microstructure of $14 \% \mathrm{SiC}$-containg composites by SEM is shown in Figure 5(a). The microstructure can be counted as having homogenous distribution and interconnection. But at some points porosity is also observed. XRD images give the structure of the particles (Figure 5 (b)). The results of spectrum analysis are listed in Table III.

TABLE III. CONTENTS OF XRD SPECTRUM

\begin{tabular}{|c|c|c|c|c|c|c|}
\hline & $\mathbf{C}$ & $\mathbf{O}$ & $\mathbf{A L}$ & $\mathbf{S i}$ & $\mathbf{C u}$ & $\mathbf{Z n}$ \\
\hline $\mathbf{1}$ & 4.49 & 2.69 & 44.2 & 45.3 & 69.5 & 3.18 \\
\hline $\mathbf{2}$ & 2.74 & 1.17 & 87.8 & 0.23 & 1.64 & 6.47 \\
\hline $\mathbf{3}$ & 29.2 & 0.73 & 0.48 & 69.5 & 0.05 & 0 \\
\hline
\end{tabular}

\section{CONCLUSIONS}

AA7075 alloys reinforced with $\mathrm{SiC}$ aluminum matrix composites were manufactured by stir casting method. SEM figures show the nearly uniform distribution of $\mathrm{SiC}$ particles in the matrix and a good bonding. Some porosity was noticed in the micrograph. The mechanical properties of the aluminum matrix composites change with respect to their $\mathrm{SiC}$ content.

\section{ACKNOWLEDGMENT}

Authors wish to acknowledge the help from Karabuk University Scientific Research Coordinatorship (Project No. KBU-BAP-15/1-DR-027).

\section{REFERENCES}

[1] D. B. Miracle, "Metal matrix composites - From science to technological significance", Composites Science and Technology, Vol. 65, No. 15-16, pp. 2526-2540, 2005

[2] M. M. Dave, K. D. Kothari, “Composite Material-Aluminium Silicon Alloy: A Review”, Indian Jopurnal of Research, Vol. 2, No. 3, pp. 148150, 2013

[3] V. K. Lindroos, M. J. Talvitie, "Recent advances in metal matrix composites", Journal of Materials Processing Technology, Vol. 53, No. 1-2, pp. 273-284, 1995

[4] A. Demir, N. Altinkok, "Effect of gas pressure infiltration on microstructure and bending strength of porous Al2O3/SiC-reinforced aluminium matrix composites", Composites Science and Technology, Vol. 64, No. 13-14, pp. 2067-2074, 2004

[5] T. Fiedler, M. A. Sulong, V. Mathier, I. V. Belova, C. Younger, G. E Murch, "Mechanical properties of aluminium foam derived from infiltration casting of salt dough", Computational Materials Science, Vol. 81, pp. 246-248, 2014

[6] S. Naher, D. Brabazon, L. Looney, "Development and assessment of a new quick quench stir caster design for the production of metal matrix composites", Journal of Materials Processing Technology, Vol. 166, No. 3, pp. 430-439, 2005

[7] D. R. J. Selvam, D. R. I. Dinaharan, "Synthesis and characterization of Al6061-Fly Ashp-SiCp composites by stir casting and compocasting methods", Energy Procedia, Vol. 34, pp. 637-646, 2013

[8] S. J. Abraham, S. C. R. Madane, I. Dinaharan, L. J. Baruch, "Development of quartz particulate reinforced AA6063 aluminum matrix composites via friction stir processing", Journal of Asian Ceramic Societies, Vol. 4, No. 4, pp. 381-389, 2016

[9] C. G. Kang, K. S. Yun, "Fabrication of metal-matrix composites by the die-casting technique and the evaluation of their mechanical properties", Journal of Materials Processing Technology, Vol. 62, No. 1-3, pp. 116123, 1996

[10] M. Mohammadpour, R. Azari Khosroshahi, R. Taherzadeh Mousavian, D. Brabazon, "Effect of interfacial-active elements addition on the 
incorporation of micron-sized $\mathrm{SiC}$ particles in molten pure aluminum", Ceramics International, Vol. 40, No. 6, pp. 8323-8332, 2014

[11] F. Delannay, L. Froyen, A. Deruyttere, "The wetting of solids by molten metals and its relation to the preparation of metal-matrix composites composites", Journal of Materials Science, Vol. 22, No. 1, pp. 1-16, 1987

[12] B. C. Kandpal, J. Kumar, H. Singh, "Fabrication and characterisation of Al2O3/aluminium alloy 6061 composites fabricated by Stir casting", Materials Today: Proceedings, Vol. 4, No. 2A, pp. 2783-2792, 2017

[13] S. W. Lim, Y. Nishida, "High Strain Rate Superplasticity of S \& N , Whisker Reinforced 7075 Alloy Matrix", Scripta Metallurgica et Materialia, Vol. 32, No. 11, pp. 1821-1825, 1994

[14] W. Chen, Y. Liu, C. Yang, D. Zhu, Y. Li, “(SiCp+Ti)/7075Al hybrid composites with high strength and large plasticity fabricated by squeeze casting”, Materials Science and Engineering: A, Vol. 609, pp. 250-254, 2014

[15] C. Kannan, R. Ramanujam, "Comparative study on the mechanical and microstructural characterisation of AA 7075 nano and hybrid nanocomposites produced by stir and squeeze casting", Journal of Advanced Research, Vol. 8, No. 4, pp. 309-319, 2017

[16] S. V. Nair, J. K. Tien, R. C. Bates, "SiC-reinforced aluminium metal matrix composites", International Metals Reviews, Vol. 30, No. 1, pp. 275-290, 1985

[17] R. N. Rao, S. Das, "Effect of SiC content and sliding speed on the wear behaviour of aluminium matrix composites", Materials \& Design, Vol. 32, No. 2, pp. 1066-1071, 2011

[18] R. Singh, G. Singh, "Investigations of Al-SiC AMC prepared by vacuum moulding assisted stir casting", Journal of Manufacturing Processes, Vol. 19, pp. 142-147, 2015

[19] W. Zhou, Z. M. Xu, "Casting of SiC reinforced metal matrix composites", Journal of Materials Processing Technology, Vol. 63, No. 1-3, pp. 358-363, 1997

[20] M. R. Akbarpour, S. Alipour, A. Safarzadeh, H. S. Kim, "Wear and friction behavior of self-lubricating hybrid $\mathrm{Cu}-(\mathrm{SiC}+\mathrm{xCNT})$ composites", Composites Part B: Engineering, Vol. 158, pp. 92-101, 2019

[21] M. J. Shen, X. J. Wang, C. D. Li, M. F. Zhang, X. S. Hu, M. Y. Zheng, $\mathrm{K}$. Wu, "Effect of submicron size $\mathrm{SiC}$ particles on microstructure and mechanical properties of AZ31B magnesium matrix composites", Materials \& Design, Vol. 54, pp. 436-442, 2014

[22] H. R. Ezatpour, M. Torabi-Parizi, S. A. Sajjadi, "Microstructure and mechanical properties of extruded $\mathrm{Al} / \mathrm{Al} 2 \mathrm{O} 3$ composites fabricated by stir-casting process", Transactions of Nonferrous Metals Society of China, Vol. 23, No. 5, pp. 1262-1268, 2013

[23] V. N. Tran, S. Yang, T. A. Phung, "Microstructure and properties of $\mathrm{Cu} / \mathrm{TiB} 2$ wear resistance composite coating on $\mathrm{H} 13$ steel prepared by insitu laser cladding", Optics \& Laser Technology, Vol. 108, pp. 480-486, 2018

[24] Y. Zhan, G. Zhang, "Friction and wear behavior of copper matrix composites reinforced with $\mathrm{SiC}$ and graphite particles", Tribology Letters, Vol. 17, No. 1, pp. 91-98, 2004

[25] R. K. Gupta, S. P. Mehrotra, S. P. Gupta, "Evaluation and optimization of metal matrix composite strip produced by single roll continuous strip casting method", Materials Science and Engineering: A, Vol. 465, No. 12, pp. 116-123, 2007

[26] A. V Pozdniakov, V. S. Zolotorevskiy, R. Y. Barkov, A. Lotfy, A. I. Bazlov, "Microstructure and material characterization of 6063 / B 4 C and $1545 \mathrm{~K} / \mathrm{B} 4 \mathrm{C}$ composites produced by two stir casting techniques for nuclear applications", Journal of Alloys andCompounds, Vol. 664, pp. 317-320, 2016 